\title{
Determination of the Dependence of Thermal Diffusivity with Moringa Concentration by Thermal Lens as a Sensitive Experimental Technique
}

\author{
R. Carbajal-Valdéz ${ }^{1} \cdot$ J. L. Jiménez-Pérez ${ }^{1}$ (D) G. Gamboa-López ${ }^{2}$. \\ Z. N. Correa-Pacheco ${ }^{3} \cdot$ C. Hernández-Aguilar ${ }^{4} \cdot M$. Pérez-González ${ }^{5}$. \\ U. O. García-Vidal ${ }^{1} \cdot$ A. Netzahual-Lopantzi ${ }^{1}$
}

Received: 28 April 2020 / Accepted: 19 May 2020 / Published online: 29 May 2020

(c) Springer Science+Business Media, LLC, part of Springer Nature 2020, corrected publication 2020

\begin{abstract}
The use of photothermal techniques has become of special importance due to their versatile application in the thermal characterization of materials. Therefore, the thermal lens technique in the mismatched dual-beam mode is an alternative, sensitive and non-evasive tool that was used in this research to determine the thermal diffusivity of Moringa oleifera. The dual arrangement of the thermal lens technique is based on the use of an $\mathrm{Ar}^{+} \mathrm{Xe}$ excitation laser (422 nm) and a He-Ne laser $(632 \mathrm{~nm})$ test laser. Moringa solutions were prepared by green synthesis with different concentrations ranging from $1.56 \mathrm{mg} \cdot \mathrm{mL}^{-1}, 3.12 \mathrm{mg} \cdot \mathrm{mL}^{-1}, 6.25 \mathrm{mg} \cdot \mathrm{mL}^{-1}$ to $12.50 \mathrm{mg} \cdot \mathrm{mL}^{-1}$. Different optical techniques (UV-vis, FTIR, XPS and EDS) were used to characterize the Moringa leaf powders. Results showed that the increase of thermal diffusivity could be related to the presence of functional groups and metallic elements in Moringa elemental composition. In this work, it was found that the thermal diffusivity of Moringa increases with increasing concentration. This study will be useful for application in heat transport and drug release.
\end{abstract}

Keywords Laser · Optical techniques · Thermal diffusivity · Thermal lens

\section{Introduction}

Among the photothermal techniques that are used to determine the thermal conductivity, effusivity or diffusivity of different solid, liquid and gaseous materials, thermal lens spectroscopy (TLS) is a versatile, sensitive and nondestructive tool employed for semitransparent samples. This technique is based on the use of two lasers: a pumping laser that excites the sample and causes a variation in the

\section{J. L. Jiménez-Pérez}

jimenezp@fis.cinvestav.mx

Extended author information available on the last page of the article 
temperature and refractive index of the material, and a second probe laser, which is guided at this point, inducing a deviation of the laser in a convergent or divergent way depending on the type of sample to be studied. This effect is called thermal lens (TL). The thermal lens technique has been successfully applied for the measurement of samples with low optical absorption and thermal diffusivity, and for different organic solvents, edible oils, biodiesels and various complex materials [1].

The investigation of the properties of Moringa oleifera extract is of special importance because it has many beneficial properties for health, nutrition and cosmetics, among others. Moringa oleifera extract is a complex mixture of chemical compounds that provide its characteristic taste and color. These chemical compounds mainly include three groups: methylene, hydroxyl $(-\mathrm{OH})$ and amino $\left(-\mathrm{NH}_{3}{ }^{+}\right)$. However, the chemical composition depends on the cultivation climate, the time of harvest, the biotype of the plant, and finally, the extraction process [2-9].

There are many properties of the Moringa oleifera which can be supplied in different forms, extract of whole or ground leaves, or from the stem. This extract can be consumed as tea and in the form of commercial drinks. Its consumption has great health benefits to fight against different diseases, such as fatigue, cholesterol, diabetes. It has been shown to be effective in reducing blood sugar levels within $3 \mathrm{~h}$ of ingestion; although it is less effective than the standard of hypoglycemic drugs such as glibenclamide. It is also useful for arthritis and prevents cancer because it contains a large amount of antioxidants (polyphenols) that destroy free radicals of organisms [2-5]. Different nutrients and minerals have been found in Moringa oleifera, i.e., $30 \%$ high-quality proteins in vitamins A and C. Moringa has four times more calcium than cow's milk, four times more iron than spinach, three times more potassium than bananas and contains $25 \%$ of fiber. Moringa could also be used in food condiments [2-6]. For example, in cosmetics, Moringa oleifera oil has many benefits when used rubbed in the body. In the skin of the face it acts as antiinflammatory; it is useful for acne's treatment, for the prevention of wrinkles and preventing premature aging. Hair benefits include dandruff reduction, hair strengthening and shine promotion. It is also ideal as an active carrier used in the production of perfumes and bar soaps [2-7]. Therefore, the importance of Moringa chemical composition, the variety of methods of preparation and purification, and the use of analytical techniques make necessary to determine their composition. In this work, the thermal diffusivity of Moringa oleifera extracts with different concentration was studied using thermal lens spectroscopy (TLS). This study could be important in the food and pharmaceutical industries. For example, it would be useful for drug release rate determination due to diffusion coefficient of the drug through the encapsulating agent [10]. The results of this work are reported for the first time for Moringa, including its thermo-optical characterization and its physico-chemical properties.

\section{Materials and Methods}

The aqueous extract was obtained by adding $2.5 \mathrm{~g}$ of grounded leaves to $1 \mathrm{~L}$ of distilled water under stirring until homogenization using temperature. Subsequently, it was allowed to cool. Finally, the Moringa oleifera extract was filtered [5]. Different 
concentrations of Moringa extracts with distilled water as semi-transparent liquids were used to perform the measurements by thermal lens at room temperature. The concentrations were M1 (1.56 $\left.\mathrm{mg} \cdot \mathrm{mL}^{-1}\right), \mathrm{M} 2\left(3.12 \mathrm{mg} \cdot \mathrm{mL}^{-1}\right), \mathrm{M} 3\left(6.25 \mathrm{mg} \cdot \mathrm{mL}^{-1}\right)$ and M4 (12.50 $\left.\mathrm{mg} \cdot \mathrm{mL}^{-1}\right)$ as shown in Fig. 1.

The obtained Moringa oleifera extract was characterized by different techniques to determine its thermal properties, surface plasmon resonance and the presence of chemical groups: thermal lens spectroscopy, UV-VIS absorption spectroscopy (Genesis 10S UV-vis), Fourier transform infrared spectroscopy (FTIR) with a Bruker Alpha FTIR from $400 \mathrm{~cm}^{-1}$ to $4000 \mathrm{~cm}^{-1}$ and a step of $2 \mathrm{~cm}^{-1}$, and X-ray photoelectron spectrometry (XPS) using a Thermo Scientific K-Alpha spectrometer equipped with a monochromated AlK $\alpha$ source $(\mathrm{h} \nu=1487 \mathrm{eV})$. The spot size was of $400 \mu \mathrm{m}$. Before the analysis, the samples were degassed during $12 \mathrm{~h}$ into the loadlock at a base pressure close to $1 \times 10^{-9}$ Torr. All the signals were calibrated using the $\mathrm{C} 1 \mathrm{~s}$ adventitious hydrocarbon located at $284.6 \mathrm{eV}$. For EDS analysis, an EDS 2100/2110EDS Norcian Instruments was used.

\subsection{Thermal Lens Spectroscopy (TLS)}

The Moringa extracts were thermally characterized using the thermal lens (TL) technique to obtain the thermal diffusivity. This technique consists on the incidence of two collinear lasers in a sample. One of these lasers heats the molecules of the medium by absorbing the optical power and is excited. The non-radiative excitation of these molecules results in a release of energy in the form of heat producing a local variation of the refractive index. This region acts as a converging or divergent lens of a second laser passing through this region, reducing the intensity which is directed to the sensor to obtain a signal corresponding to the thermal lens.

The experimental setup of TL is shown in Fig. 2. The measurement of the TL signal was carried out using a $40-\mathrm{mW} \mathrm{Ar}^{+} \mathrm{Xe}$ laser (Spectra) emitting at $\lambda=442 \mathrm{~nm}$ as excitation laser and a second laser of $\mathrm{He}-\mathrm{Ne}, \lambda=632.5 \mathrm{~nm}$ as a probe laser. A mechanical

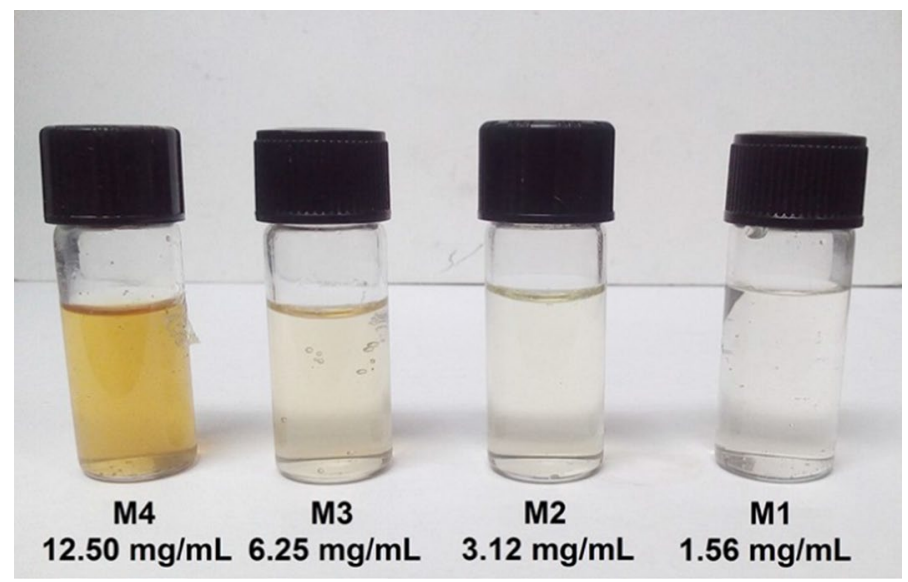

Fig. 1 Different concentrations of Moringa extract in distilled water 


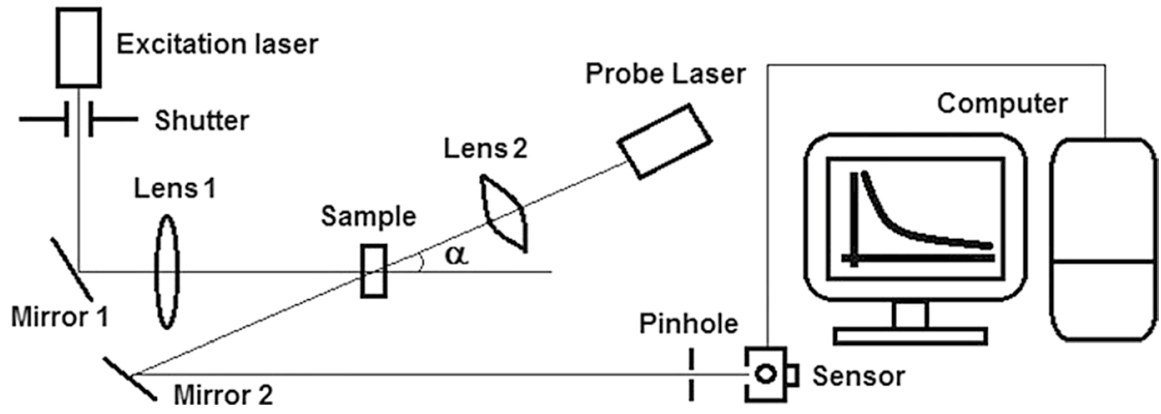

Fig. 2 Schematic representation of mode mismatched dual-beam thermal lens technique

shutter was used to limit the excitation light beam to the sample. This was focalized by a lens focal length in a liquid sample contained in a 1-cm long quartz cuvette, positioned in the focal plane. A second aligned probe laser, to a small angle, was focused by a lens focal length, oppositely directed to the excitation laser.

The light from the transmitted probe beam was recorded by a photodiode. The sensor was coupled to a National Instrument card to record the time evolution of the thermal lens signal as showed in Fig. 2. Labview software was used to control and capture TL data and normalizes this signal with respect to the initial time signal. The experimental data were adjusted using the theoretical Eq. 1 with the constant $t_{c}$, the characteristic time of TL (Eq. 4) and $\theta$ (Eq. 5) as adjustment parameters. Hence, the thermal diffusivity of the sample was calculated from Eq. 4. This process was used for all the experimental data to obtain the thermal diffusivity of the samples.

\subsection{Theory}

Shen et al. [11] derived from a theoretical expression a theory relation for the signal $I(t)$ of the intensity of the excitation probe beam with a diffraction approximation for the Gaussian beam in the following way:

$$
I(z, t)=I_{0}\left(1-\theta \tan ^{-1}\left(\frac{2 m V}{\left[(1+2 m)^{2}+V^{2}\right] \frac{t_{c}}{2 t}+1+2 m+V^{2}}\right)\right)^{2}
$$

where

$$
\begin{gathered}
V=\frac{Z_{1}}{Z_{c}} \\
m=\left(\frac{w_{p}}{w_{e}}\right)^{2}
\end{gathered}
$$




$$
\begin{gathered}
t_{c}=\frac{w_{e}^{2}}{4 D} \\
\theta=\frac{P_{e} \alpha L}{k \lambda_{p}} \frac{d_{n}}{d_{T}}
\end{gathered}
$$

where $I(t)$ is the signal transmitted from the probe beam to the detector as a function of time and normalized with $I(0)$ which is the initial intensity of $I(t), V$ is a constant parameter, $Z_{l}$ is the distance from the probe beam waist to the sample, $Z_{c}=w_{p}^{2} / \lambda_{p}$ is the confocal distance $(\mathrm{cm}), w_{p}$ and $w_{e}$ are the ratio of the probe and excitation beam of the sample, respectively, $t_{c}$ is the characteristic thermal time constant, $\lambda_{\mathrm{L}}$ and $\lambda_{\mathrm{p}}$ are the wavelength of the excitation and probe beam, respectively, $D=k / \rho c_{p}$ is the thermal diffusivity of the sample; $k$ is the thermal conductivity and $\rho$ the fluid density, $P_{e}$ is the power of the excitation beam, $\alpha$ is the absorption coefficient and $L$ is the thickness of the sample. $\mathrm{dn} / \mathrm{dT}$ is the refractive index dependent on the temperature of the sample. Table 1 summarizes the experimental parameters that were used for the TL measurement and the liquid Moringa extract were subjected to sonication to ensure a good dispersion.

\section{Results and Discussions}

\subsection{Measurement of Diffusivity with TLS}

The evolution of the normalized thermal lens signal for different concentrations of Moringa extract is shown in Fig. 3. The solid line is the better fit of the Eq. 1 to the experimental data. The characteristic time $t_{c}$ of the thermal lens formation on the sample is given in milliseconds, and with this value of $t_{c}$ the thermal diffusivity value can be obtained using Eq. 4 . For each concentration $1.56 \mathrm{mg} \cdot \mathrm{mL}^{-1}$, $3.12 \mathrm{mg} \cdot \mathrm{mL}^{-1}, 6.25 \mathrm{mg} \cdot \mathrm{mL}^{-1}$ and $12.50 \mathrm{mg} \cdot \mathrm{mL}^{-1}$, the thermal diffusivity values

Table 1 Thermal lens experiment parameters

\begin{tabular}{ll}
\hline $\mathrm{P}_{\mathrm{e}}-$ Excitation laser power $\left(\lambda_{\mathrm{L}}=442 \mathrm{~nm}\right)$ & $40 \mathrm{~mW}$ \\
$\mathrm{P}_{\mathrm{p}}$-Probe laser power (at $\left.632.8 \mathrm{~nm}\right)$ & $1 \mathrm{~mW}$ \\
$\omega_{\mathrm{e}}-$ Excitation laser spot size & $4.9 \times 10^{-3} \mathrm{~cm}$ \\
$\omega_{1 \mathrm{p}}$-Probe laser spot size at cell & $1.81 \times 10^{-2} \mathrm{~cm}$ \\
$\mathrm{~m}-$ Constant parameter & 13.691 \\
$\mathrm{~V}-$ Constant parameter & 1.22 \\
$\mathrm{Z}_{\mathrm{c}}$-Focal distance & $6.56 \mathrm{~cm}$ \\
$\mathrm{Z}_{2}-$ Distance & $\sim 2 \mathrm{~m}$ \\
$\mathrm{~L}-$ Length of sample cell & $1.0 \mathrm{~cm}$ \\
Sample & Moringa oleifera \\
& aqueous leaf \\
\hline
\end{tabular}




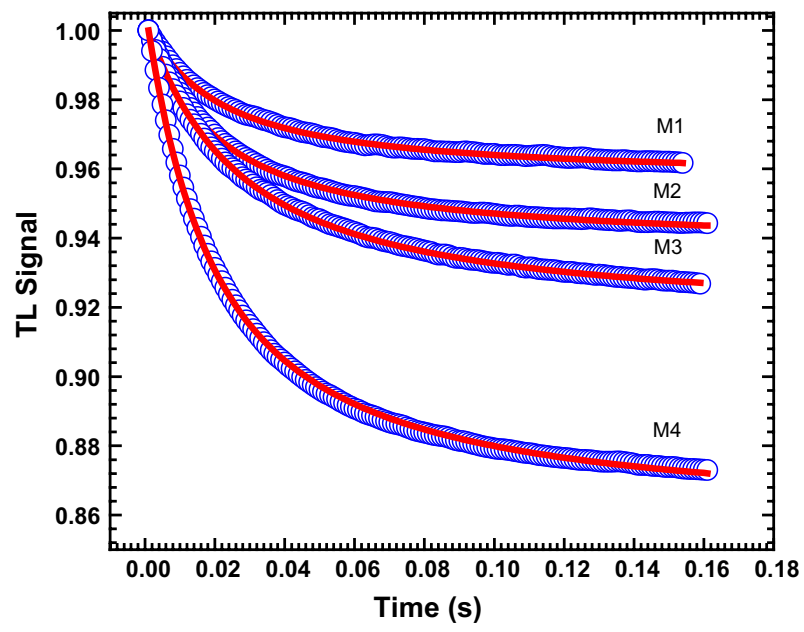

Fig. 3 The evolution of the intensity of solid curves is the best fit to Eq. 1 to the thermal lens signal as a function of time for different concentrations of Moringa (mg)/distilled water (mL), M1 to M4

were obtained: $1.75 \pm 0.07,1.80 \pm 0.03,1.81 \pm 0.05$ and $1.96 \pm 0.02 \times 10^{-3} \mathrm{~cm}^{2} \cdot \mathrm{s}^{-1}$, respectively. For the calibration of the TL technique, distilled water was used where its thermal diffusivity is $1.14 \times 10^{-3} \mathrm{~cm}^{2} \cdot \mathrm{s}^{-1}$, in agreement with the values reported in the literature $[12,13]$. The propagation of error to find the error of the thermal diffusivity was used. Table 2 summarizes the results of the concentrations in $\mathrm{mg} \cdot \mathrm{mL}^{-1}$ and the diffusivities obtained by thermal lens. Also, the comparison of the concentrations proposed in this work with other researchers is shown. It is observed that dosage values are like to those found in this work. Initially, when the experimental part was designed, similar values to that of the cited from the literature were used. However, as mentioned before, the thermal lens signal depends on the wavelength

Table 2 Thermal diffusivity and different concentrations of Moringa oleifera extract

\begin{tabular}{|c|c|c|c|}
\hline $\begin{array}{l}\text { Extract } \\
\text { concentration } \\
\left(\mathrm{mg} \cdot \mathrm{mL}^{-1}\right)\end{array}$ & $\begin{array}{l}\text { Diffusiv- } \\
\text { ity } \times 10^{-3} \\
\left(\mathrm{~cm}^{2} \cdot \mathrm{s}^{-1}\right)\end{array}$ & $\begin{array}{l}\text { Extract concentration } \\
\left(\mathrm{mg} \cdot \mathrm{mL}^{-1}\right) \text { literature }\end{array}$ & Applications \\
\hline 1.56 & $1.75 \pm 0.007$ & 1.0 to 0.125 & $\begin{array}{l}\text { Moringa shell for cancer treatment (antioxi- } \\
\text { dant) [14] }\end{array}$ \\
\hline 3.12 & $1.80 \pm 0.003$ & 2.5 to 0.312 & $\begin{array}{l}\text { Moringa shell for cancer treatment (antioxi- } \\
\text { dant) [14] }\end{array}$ \\
\hline 6.25 & $1.81 \pm 0.005$ & 5.00 & $\begin{array}{l}\text { Moringa leaves for Escherichia coli (antibac- } \\
\text { terial) [15] }\end{array}$ \\
\hline \multirow[t]{2}{*}{12.50} & $1.96 \pm 0.003$ & 10.00 & $\begin{array}{l}\text { Moringa leaves for Candida Albicans, } \\
\text { Penicillium Notatum and Aspergillus flavus } \\
\text { (antifungal) [15] }\end{array}$ \\
\hline & & 80 to 5 & $\begin{array}{l}\text { Moringa leaves extract for hypercholester- } \\
\text { olemia, hyperglycemia and nutritional } \\
\text { supplement (nutraceutic) [16] }\end{array}$ \\
\hline
\end{tabular}


and concentration. For lower concentrations in the measurements, the thermal lens signal was decreased, with a higher level of uncertainty. Therefore, higher concentrations were used to determine more accurately the dose-dependent increase of diffusivity.

The value of $\theta$ is dependent on the optical energy in the length $\lambda_{L}$, of the parameter $\mathrm{dn} / \mathrm{dT}$ which is the variation of the refraction index with the temperature, the thermal conductivity $k$ and $\alpha$ that the absorbance of the sample through Eq. 5. In Fig. 4, the parameter $\theta$ is shown as a function of the concentration of Moringa. There was an increase of the parameter $\theta$ with the increase in concentration. Since only absorbed photons contribute to the thermal lens signal through non-radiative excitation, this technique is sensitive to low concentrations such as traces of some adulterants in water, for example, residual contaminants of water chromium [17].

In Fig. 5, the increase in thermal diffusivity as a function of the concentration of Moringa extract can be observed. It had a linear behavior with the increase in concentration. When the increase in thermal diffusivity with the concentration of Moringa is compared with the thermal diffusivity of water, an enrichment of $26 \%$ to $39 \%$ is observed.

\subsection{UV-Vis Spectra}

Figure 6 shows the UV-Vis spectra for the different concentrations of Moringa. The characteristic absorption peaks at $270 \mathrm{~nm}$ and $326 \mathrm{~nm}$ are related to the presence of chlorophyll b in Moringa oleifera for concentrations $\mathrm{M} 1$ and $\mathrm{M} 2,1.56 \mathrm{mg} \cdot \mathrm{mL}^{-1}$ and $3.12 \mathrm{mg} \cdot \mathrm{mL}^{-1}$, respectively $[5,18]$. The M3 and M4 samples had a higher concentration of $6.26 \mathrm{mg} \cdot \mathrm{mL}^{-1}$ to $12.50 \mathrm{mg} \cdot \mathrm{mL}^{-1}$, for which the chlorophyll $\mathrm{b}$ peaks have low intensity.

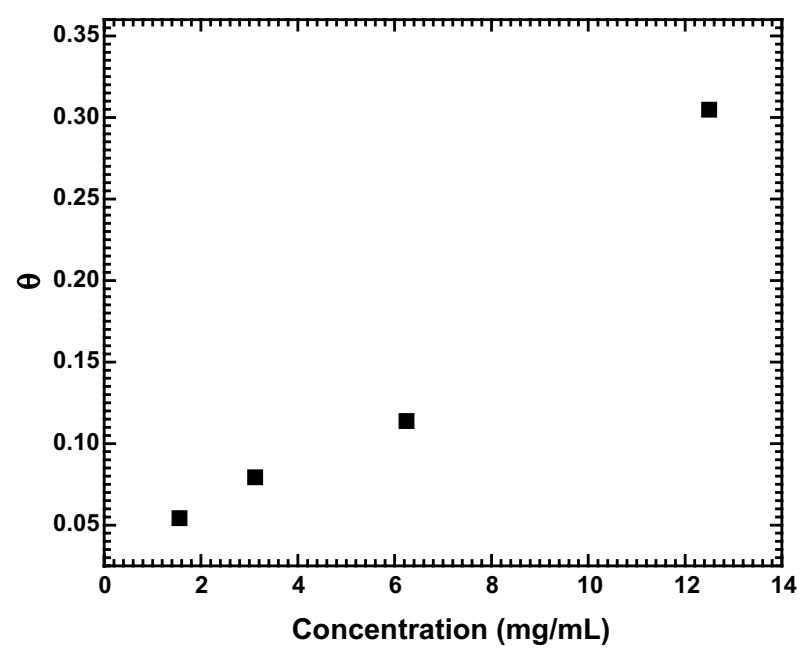

Fig. 4 Evolution of $\theta$ parameter with Moringa concentration 


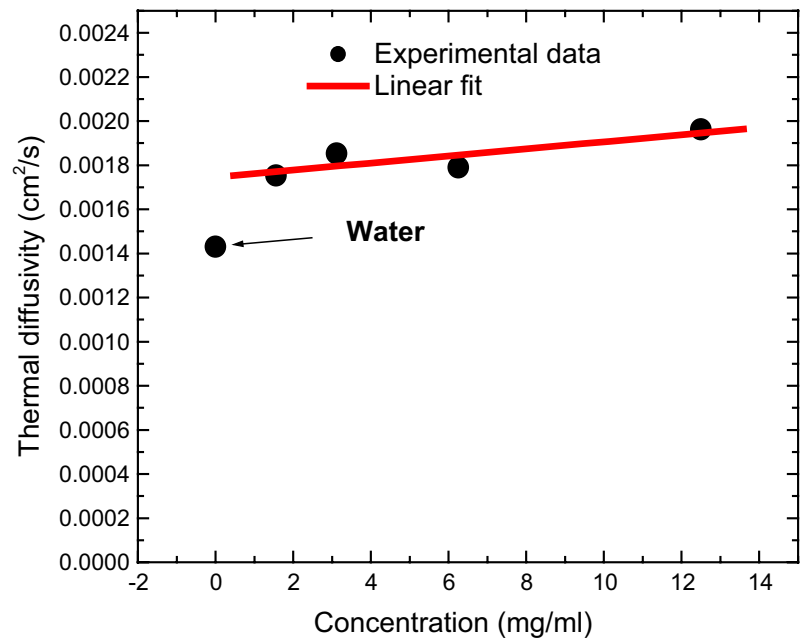

Fig. 5 Thermal diffusivity dependence on the concentration of the Moringa/water $\left(\mathrm{mg} \cdot \mathrm{mL}^{-1}\right)$. The solid line is the best fitting to the experimental values. $\mathrm{R}^{2}=0.84$. Distilled water thermal diffusivity $=1.14 \times 10^{-3} \mathrm{~cm}^{2} \cdot \mathrm{s}^{-1}$

Fig. 6 UV-vis absorption spectra with concentrations of Moringa extract

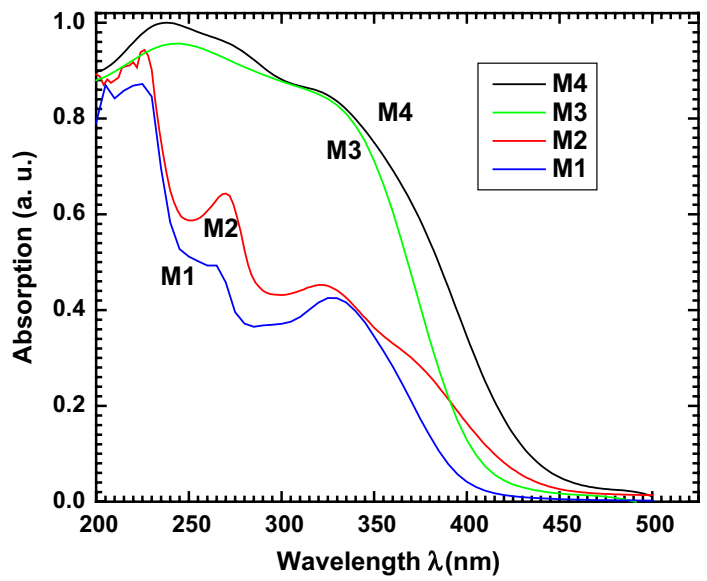

The absorption intensity in the excitation laser wavelength at $\lambda_{\mathrm{L}}=442 \mathrm{~nm}$ of Fig. 5 was plotted as shown in Fig. 7. The increase of absorption as a function of concentration can be seen. According to the absorption spectrum with the Moringa concentration in Fig. 6 , for a laser with $\lambda=422 \mathrm{~nm}$, the absorption coefficients in that wavelength are increasing and not linear. This may be due to the concentration of Moringa, according to Beer's law.

To clearly state the uncertainty for each experimental value in Table 2 , the optical absorption is different for each concentration as can be seen in Fig. 6. For the $422 \mathrm{~nm}$ wavelength, the absorption coefficient at this wavelength varies from 


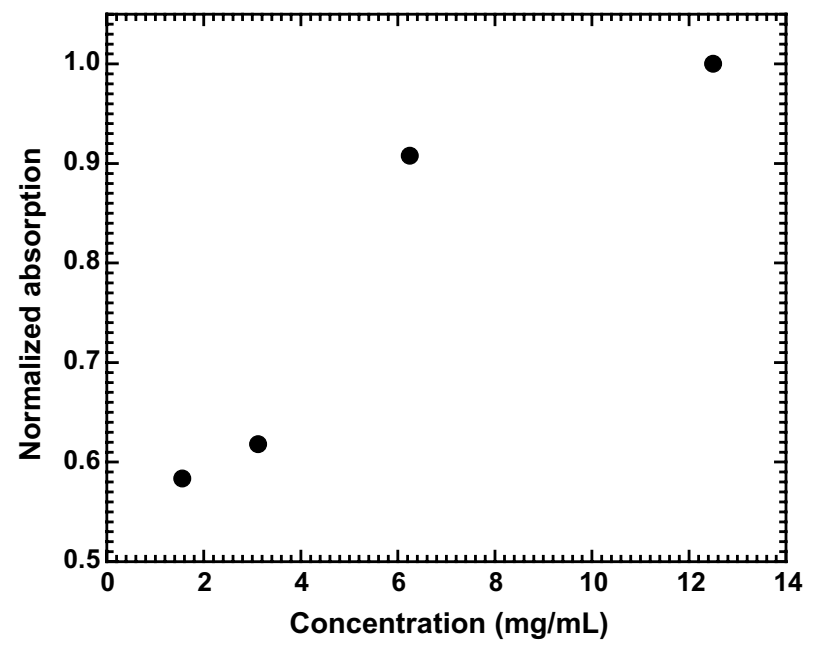

Fig. 7 Absorption intensity at $\lambda_{\mathrm{L}}=442 \mathrm{~nm}$ as a function of Moringa concentration

$1 \%$ to $16 \%$ as the concentration increases. Therefore, the thermal lens signal is also increased; then, the error tends to reduce.

\subsection{Fourier Transform Infrared Spectroscopy (FTIR)}

In the FTIR spectra from Fig. 8, methylene groups $=\mathrm{CH}_{2},-\mathrm{OH}$ groups and amino groups $-\mathrm{NH}_{3}$ are observed. The main chemical groups present in the Moringa [19] in the range between $2910 \mathrm{~cm}^{-1}$ and $2854 \mathrm{~cm}^{-1}$ are assigned to methylene

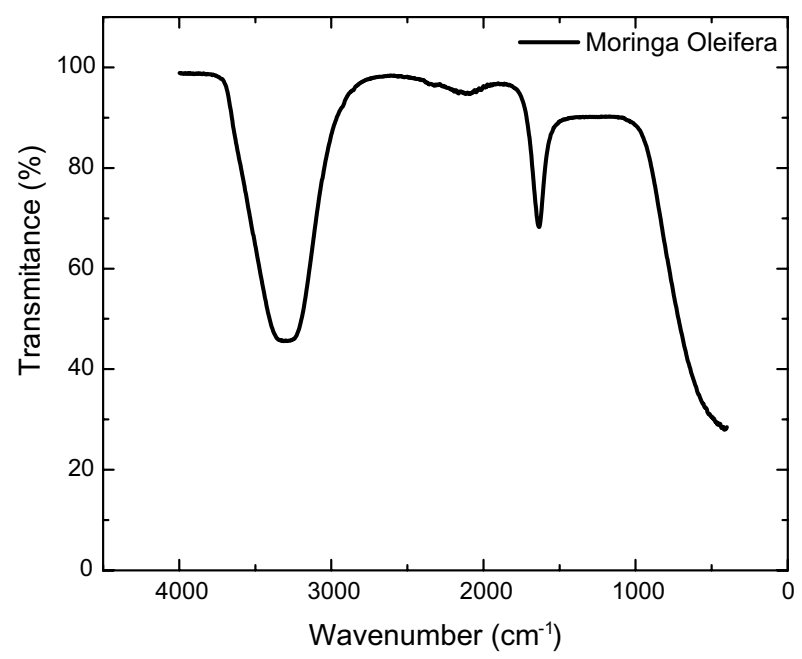

Fig. 8 FTIR spectrum of Moringa oleifera 
asymmetrical stretching group; a small band located at $2375 \mathrm{~cm}^{-1}$ to $2285 \mathrm{~cm}^{-1}$ corresponds to the asymmetric stretching vibration of $\mathrm{N}-\mathrm{H}$ in an $-\mathrm{NH}_{3}{ }^{+}$group. In the region between $2561 \mathrm{~cm}^{-1}$ and $2515 \mathrm{~cm}^{-1}$ there is a peak related to hydrogen bonded to $\mathrm{O}-\mathrm{H}$ stretching vibration of carboxylic acid, associated by hydrogen bonding groups. At $1730 \mathrm{~cm}^{-1}$ there is a sharp peak related to $\mathrm{C}=\mathrm{O}$ stretching for the main bioactive compounds in Moringa like flavonoids, glucosides, and glucosinolates and to chlorophyll $[20,21]$.

\subsection{X-Ray Photoelectron Spectroscopy Analysis}

The surface chemical composition of Moringa oleifera was obtained by XPS analysis measurements. To our knowledge, only a few works have reported the XPS analysis for some applications of Moringa oleifera as a corrosion protector applied to carbon steel [22], as a reductor agent for the green synthesis of $\mathrm{Ni} / \mathrm{Fe}_{3} \mathrm{O}_{4}$ magnetic nanoparticles [23], or as a carbon precursor to produce high-valued carbon nanomaterials [24]. XPS values have not been reported in the literature for single Moringa oleifera in powder form. As shown in Fig. 9, the XPS survey spectra for Moringa oleifera demonstrated that its main components are carbon $(\mathrm{C} 1 \mathrm{~s})$, oxygen $(\mathrm{O} 1 \mathrm{~s})$, and nitrogen (N 1s). Using a Shirley background, the surface elemental composition was calculated as displayed. As a result, an atomic \% of 81.99 was found for C $1 \mathrm{~s}$, $14.61 \%$ for $\mathrm{O} 1 \mathrm{~s}, 2.08 \%$ for $\mathrm{N} 1 \mathrm{~s}$ and $1.32 \%$ for other elements. Considering the organic nature of Moringa oleifera that contains bioactive compounds and cellulose, hemicellulose, and lignin, the peaks found in this work can be attributed to the same compounds [25-27].

In Fig. 10, the EDS analysis for the Moringa extract shows different elements such as $\mathrm{K}, \mathrm{Ca}$ in higher proportions than $\mathrm{P}, \mathrm{S}, \mathrm{Ti}, \mathrm{Fe}, \mathrm{Cu}$ and other elements such

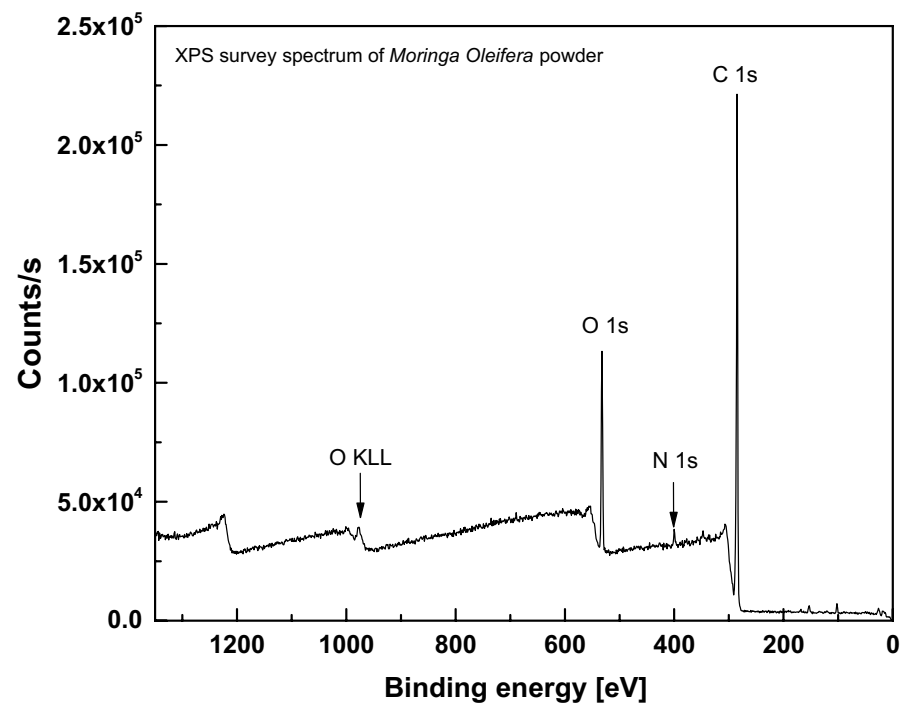

Fig. 9 XPS spectra for Moringa oleifera powder sample. (a) Survey, (b) C 1s, (c) O 1s, and (d) N 1s 


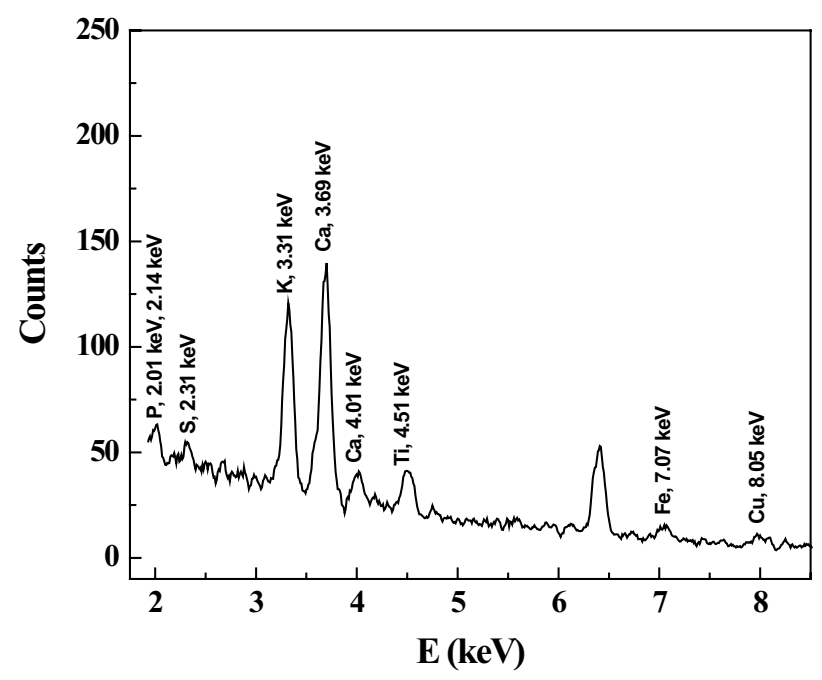

Fig. 10 EDS spectra for Moringa oleifera powder sample

as $\mathrm{Na}, \mathrm{Mg}, \mathrm{Al}, \mathrm{O}$ and $\mathrm{C}$ which correspond to elements in smaller proportion, not shown here. As reported by other authors [28], in the EDS analyzes they found $\mathrm{Ca}$, $\mathrm{Mg}, \mathrm{Na}$ and $\mathrm{Fe}$ of the Moringa seed. On the other hand, high concentrations of $\mathrm{Ca}$, $\mathrm{Mg}, \mathrm{Zn}, \mathrm{Na}$ and $\mathrm{Cu}$ were also found in the pericarp. As expected, in the chemical composition of the Moringa several metallic elements were found, and these results are like those of this work.

From the previous results, in the UV-visible spectrum (absorbance versus concentration) and from the parameter $\theta$ which is a function of the concentration, an increase in absorbance with an increase in concentration was observed. Using the analytical techniques from FTIR it was found that in the Moringa extract, important functional groups like hydroxyl, carboxyl and amino are present in minor proportion in its structure. XPS showed the presence of carbon, oxygen and nitrogen elements. In EDS analysis, several metals such as $\mathrm{Fe}, \mathrm{Cu}$, $\mathrm{Ti}$ and $\mathrm{Al}$ and other nonmetals ( $\mathrm{S}$, $\mathrm{P}, \mathrm{K}$ and $\mathrm{Ca}$ ) were found. Therefore, the increase and enhancement in thermal diffusivity of Moringa extract could be due to the presence of metallic elements in its composition. It can be seen that with the presence of metallic groups, the spectrum of the TL signal has a more pronounced shape and the experimental values better fit the theoretical curve (see spectrum M4 in Fig. 3). Another authors [29] observed the improvement of the TL signal with silver nanoparticles added to the grapefruit citrus oil, a similar behavior to that obtained in this work.

It is important to highlight that the concentration of Moringa for health purposes must be established because a required dose is necessary for different applications; for example, in antioxidants, antimicrobials and in another multiple public health problems. Recently, an important disease such as Coronavirus is the focus of world attention. However, it is necessary to determine a dose of the drug that could stop the growth of SAR-CoV-2, which can effectively eradicate the genetic material of the virus [30]. Photothermal techniques such as thermal lens technique could be 
useful for such applications: drug release in the pharmaceutical, food adulteration analysis, kinetic reactions, sensors, biotechnology and in contaminant trace analysis, among others $[10,31-33]$.

\section{Conclusions}

The importance of Moringa chemical composition, the variety of methods of preparation and purification and the use of analytical techniques make necessary to determine their main optical and thermal properties. These studies are related to dosage requirements for applications as antioxidants and antimicrobials. In this work, different concentrations of Moringa were studied using thermal lens. New results related to thermal diffusivity of Moringa extract with concentration are shown. The absorption and thermal lens study shows that thermal diffusivity increases with the concentration of Moringa. Moreover, using complementary chemical analyzes, an increase of thermal diffusivity due to the presence of functional groups and metallic elements from Moringa elemental composition was observed. The results were close to doses of Moringa extracts reported in the literature. Also, it was demonstrated that thermal lens, which is a sensitive and non-destructive technique, was useful for determining the dose of a semi-transparent sample such as Moringa. The thermal diffusivity was enriched in $39 \%$ with an increase depending on the concentration of the extract. In this work, different concentrations were tested to find the optimal value for an adequate measurement of thermal properties.

Acknowledgements We would like to thank CONACYT, COFAA and CGPI-IPN, México. Also, to the Red de Nanofotónica.

\section{References}

1. A.J. De Freitas Cabral, P.C. De Oliveira, S.G.C. Moreira, S.P. Alcantara Jr., Int. J. Thermophys. 32, 1966 (2011). https://doi.org/10.1007/s10765-011-1059-y

2. F. Anwar, S. Latif, M. Ashraf, A. Gilani, Phytother. Res. 21, 17 (2007). https://doi.org/10.1002/ ptr.2023

3. F.J. González Minero, Dominguezia 34, 5 (2018)

4. I. Matic, A. Guidi, M. Kenzo, M. Mattei, A. Galgani, J. Public Health Afr. 9(3), 841:191 (2018). https://doi.org/10.4081/jphia.2018.841

5. V. Patidar, P. Jain, Int. Res. J. Eng. Technol. 4, 470 (2017)

6. T. Desale, EC Agric. 6, 01 (2020)

7. M.L. Alvarado-Noguez, C. Hernández-Aguilar, A. Domínguez-Pacheco, A. Cruz-Orea, F. SánchezSinéncio, Int. J. Thermophys. 39, 99 (2018). https://doi.org/10.1007/s10765-018-2418-8

8. C. Tiloke, A. Phulukdaree, K. Anand, R. Gengan, A. Chuturgoon, J. Cell. Biochem. 117, 2302 (2016). https://doi.org/10.1002/jcb.25528

9. E. Paul, Z. Garba, D. James, J. Appl. Sci. Environ. Manag. 23, 759 (2019). https://doi.org/10.4314/ jasem.v23i4.29

10. T. Vo, R. Yang, F. Aldabbagh, W. Carroll, M. Meere, Y. Rochev, J. Therm. Sci. Eng. Appl. 6, 021012:1 (2014). https://doi.org/10.1115/1.4025935

11. J. Shen, R. Lowe, R. Snook, Chem. Phys. 165, 385 (1992). https://doi.org/10.1016/03010104(92)87053-C 
12. R. C. Weast, Handbook of chemistry and physics, 67 edn. (Chemical Rubber Corp., Boca Ratón, 1986-1987)

13. P.R.B. Pedreira, L. Hirsch, J.R.D. Pereira, A.N. Medina, A.C. Bento, M.L. Baesso, Rev. Sci. Instrum. 74, 808 (2003). https://doi.org/10.1063/1.1517161

14. A.F. Santos, A.C. Argolo, P.M. Paiva, L.C. Coelho, Phytother. Res. 26, 1366 (2012). https://doi. org/10.1002/ptr.4591

15. M. Busani, M. Julius, M. Voster, Afr. J. Biotechnol. 11, 2797 (2012). https://doi.org/10.5897/AJB10 .686

16. G.A. Asare, B. Gyan, K. Bugyei, S. Adjei, R. Mahama, P. Addo, L. Otu-Nyarko, E.K. Wiredu, A. Nyarko, J. Ethnopharmacol. 139, 265 (2012). https://doi.org/10.1016/j.jep.2011.11.009

17. H. Cabrera, D. Korte, M. Franko, Rev. Sci. Instrum. 86, 053701:1 (2015). https://doi. org/10.1063/1.4919735

18. M. Dzagli, K. Sossoe, K. Gadedjisso-Tossou, M. Mohou, S. Boca, S. Astilean, J. Zoueu, ISESCO J. Sci. Technol. 12, 33 (2016)

19. C. Rébufa, I. Pany, N. Dupuy, I. Bombarda, Acta Hortic. 1158, 397 (2017). https://doi.org/10.17660 /ActaHortic.2017.1158.45

20. V.A. Ogundele, O.E. Fadeyi, Isolation. Nat. Prod. Chem. Res. 3, 1 (2015). https://doi. org/10.4172/2329-6836.1000189

21. J. Johnson, J. Mani, N. Ashwath, M. Naiker, Spectrochim. Acta A 233, 118228:1 (2020). https://doi. org/10.1016/j.saa.2020.118228

22. D.I. Njoku, E.E. Oguzie, Y. Li, J. Mol. Liq. 237, 274 (2017). https://doi.org/10.1016/j.molli q.2017.04.087

23. C. Prasad, K. Sreenivasulu, S. Gangadhara, P. Venkateswarlu, J. Alloys Compd. 700, 252 (2017). https://doi.org/10.1016/j.jallcom.2016.12.363

24. Y. Cai, Y. Luo, Y. Xiao, X. Zhao, Y. Liang, H. Hu, H. Dong, L. Sun, Y. Liu, M. Zheng, A.C.S. Appl, Mater. Interfaces 8, 33060 (2016). https://doi.org/10.1021/acsami.6b10893

25. W. Lou, Q. Guo, W. Chen, M. Zong, H. Wu, T. Smith, ChemSusChem 5, 1533 (2012). https://doi. org/10.1002/cssc.201100811

26. L.S. Johansson, J.M. Campbell, K. Koljonen, P. Stenius, Appl. Surf. Sci. 144, 92 (1999). https://doi. org/10.1016/S0169-4332(98)00920-9

27. J.J. Martínez, A.C. Herrera, L.R. Román, Rev. Cienc. 15, 23 (2011). https://doi.org/10.25100/ rc.v15i0.514

28. D.W. James, J. Mater. Sci. 3, 540 (1968). https://doi.org/10.1007/BF00549738

29. R. Herrera-Aquino, J.L. Jiménez-Pérez, D.C. Altamirano-Juárez, G. López-Gamboa, Z.N. Correa-Pacheco, R. Carbajal-Valdéz, Int. J. Thermophys. 40, 1 (2019). https://doi.org/10.1007/s1076 5-018-2466-0

30. Investigadores demuestran que medicamento mata en 48 horas al Covid-19 en pruebas "in vitro". https://www.eluniversal.com.mx/mundo/medicamento-mata-en-48-horas-al-covid-19-en-pruebasvitro. Accessed 05 Apr 2020

31. V. Raj, M.S. Swapna, H.V.S. Devi, S. Sankararaman, Appl. Phys. B 125, 113 (2019)

32. V. Dudko, A. Smirnova, M. Proskurnin, A. Hibara, T. Kitamori, J. Gen. Chem. 82, 2146 (2012). https://doi.org/10.1134/S1070363212120341

33. G. Mazza, T. Posnicek, L. Wagner, J. Ettenauer, K. Zuser, M. Gusenbauer, M. Brand1, Sens. Actuators B Chem. 249, 731 (2017). https://doi.org/10.1016/j.snb.2017.04.091

Publisher's Note Springer Nature remains neutral with regard to jurisdictional claims in published maps and institutional affiliations. 


\section{Affiliations}

\section{R. Carbajal-Valdéz ${ }^{1} \cdot$ J. L. Jiménez-Pérez ${ }^{1}$ (D) - G. Gamboa-López ${ }^{2}$.}

Z. N. Correa-Pacheco ${ }^{3}$. C. Hernández-Aguilar ${ }^{4} \cdot$ M. Pérez-González ${ }^{5}$.

U. O. García-Vidal ${ }^{1}$ - A. Netzahual-Lopantzi ${ }^{1}$

1 Unidad Profesional Interdisciplinaria de Ingeniería y Tecnología Avanzadas del Instituto Politécnico Nacional, Avenida Instituto Politécnico Nacional No. 2580, Col. Barrio la Laguna Ticomán, Gustavo A. Madero, C.P.07340 Mexico City, México

2 Instituto Tecnológico de Toluca, Avenida Tecnológico s/n, Colonia Agrícola Bellavista, C.P.52149 Metepec, Mexico State, Mexico

3 CONACYT-Centro de Desarrollo de Productos Bióticos, Instituto Politécnico Nacional, Carretera Yautepec-Jojutla, Km. 6, calle CEPROBI No. 8, Col. San Isidro, C.P. 62731 Yautepec, Morelos, Mexico

4 Sección de Estudios de Posgrado e Investigación-ESIME, Instituto Politécnico Nacional, Zacatenco, Unidad Profesional “Adolfo López Mateos”, Col. Lindavista, C.P. 07738 Mexico City, Mexico

5 Área Académica de Matemáticas y Física, Instituto de Ciencias Básicas e Ingeniería, Universidad Autónoma del Estado de Hidalgo, Carretera Pachuca-Tulancingo Km. 4.5, Col. Carboneras, C.P. 42184 Mineral de la Reforma, Hidalgo, Mexico 